\title{
Spontaneous nephrocolic fistula secondary to a staghorn calculus
}

\author{
Daniel E. Henao • Arturo Vásquez
}

Received: 21 December 2011 / Accepted: 18 January 2012 / Published online: 1 February 2012

(C) Springer-Verlag 2012

\begin{abstract}
A 54-year-old woman-with no past surgical history-presented to the emergency department with an 8-day history of abdominal pain in the left flank and diarrhea. Initially, the patient underwent an abdominal ultrasound that showed a lower pole kidney mass. Computed tomography was performed and revealed a fragmented staghorn calculus complicated with a xanthogranulomatous pyelonephritis in the left kidney (Fig. 1). The cleavage plane between the left kidney and the colon was undistinguished and a nephrocolic fistula (arrows) was diagnosed. To confirm this finding a barium enema was carried out: demonstrating passage of intravenous contrast from the colon to the kidney. Finally, the patient was taken to the surgery room where nephrectomy and left hemicolectomy were carried out.

Few nephrointestinal fistulae have been described in the literature, and the cases of spontaneous appearance of this condition are even scarce [1]. The most common cause of spontaneous nephrocolic fistulae involves staghorn calculi [2]. These calculi are formed of a rapidly growing stone and are mainly composed of struvite-carbonate-apatite
\end{abstract}

D. E. Henao $(\square)$

Grupo Reproducción, Facultad de Medicina, Universidad de Antioquia, Calle 63 No. 52-59,

Medellin, Colombia

e-mail: dhenaonieto@gmail.com

\section{A. Vásquez}

Sección de Urología, Departamento de Cirugía, Facultad de Medicina, Universidad de Antioquia,

Carrera 51B No. 69-13, Medellin, Colombia

e-mail: artvasquez9@yahoo.es

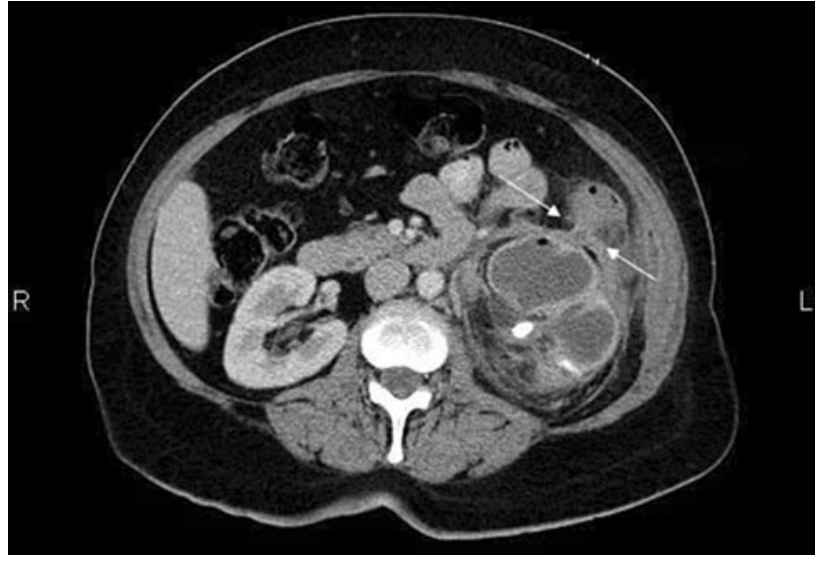

Fig. 1 Abdominal computed tomography. Axial view of the abdomen demonstrating the nephrocolic fistula (arrows) and the presence of a staghorn calculus

matrix. These stones are likely to cause great morbidity and mortality if not treated. Treatment frequently includes: percutaneous nephrolithotomy, followed by extracorporeal shock wave lithotripsy and/or flexible ureteroscopy, and laser [3]. Imaging procedures-abdominal X-rays and computed tomography - are the best diagnostic tools to be used in this condition.

\section{References}

1. Alster C, Zantut LF, Lorenzi F et al (2007) An unusual case of pneumoperitoneum: nephrocolic fistula due to giant renal staghorn calculus. Br J Radiol 80:e1-e3

2. Connor JP, Schwartz M, Lehrhoff B (1991) Nephrocolic fistula in association with a staghorn calculus discover intraoperatively. Int Urol Nephrol 23(2):113-116

3. Rocco F, Mandressi A, Larcher P (1984) Surgical classification of renal calculi. Eur Urol 10:121-123 